\title{
Research on of Logistics Technological Innovation and Logistics Information System Collaborative Linkage System based on RFID
}

\author{
Wang Qingjun \\ school of Economics and Management \\ Shenyang Aerospace University \\ Shenyang, china
}

\author{
Li Yaofei \\ school of Economics and Management \\ Shenyang Aerospace University \\ Shenyang, china
}

\begin{abstract}
Since China's reform and opening up, China's emerging third-party logistics providers investment main body presents a trend of diversification, management mechanism and market idea is market-oriented、 But the logistics enterprises of production operations are not familiar with or ability is limited, more or less can lead to the development of the logistics chain now sluggish、 Therefore, based on RFID logistics information technology innovation and the construction of logistics information system coordination system for modern logistics information management is particularly important、RFID technology and the Internet, such as information technology, telecommunications, computer technology, which can realize global logistics goods tracking and information sharing、 Adopt the RFID technology as information carrier of modern logistics information system in the mass information collection, transmission, analysis, processing, storage and maintenance of the logistics industry on the issue of played an irreplaceable role, especially in the modern logistics operation efficiency and simplify the process information management system of more highlights its remarkable superiority.
\end{abstract}

Keywords-RFID; Logistics technology; Information management system; Innovation; efficient

\section{D EVELOPMENT OVERVIEW OF CHINA'S CURRENT}

\section{LOGISTICS INDUSTRY}

\section{A. Overall development status of China's logistics industry}

China's current logistics industry shows a prosperous and depressed sign. Some trends can be simply seen from China's"logistics fever":
China's publicity coverages of logistics and logistics supply chain are increasing.

China's logistics conference and facilities and equipment exhibition is increasing.

China's demand for logistics professionals has a sharp increase.

Theories of logistics and Practice of Logistics are in the ascendant and colorful in China.

Foreign capital is optimistic about China's logistics market, and actively participates in China's logistics industry and distribution industry.

As can be seen, the development of the logistics industry or supply chain slowly prospers. It can also boldly predict that future enormous changes will take place in China's logistics industry. The total social logistics amount's momentum slows down. For example, the market survey shows that: January-August 2010, the total social logistics amount was 79.7 trillion yuan, an increase of $17.2 \%$ calculated at comparable prices, and the growth rate declined $0.4 \%$ over the January-July. Although it continued the declined growth rate in 2010, an decline of $0.4 \%$ than January-July. In total social logistics amount, the total industrial logistics amount was 71.8 trillion Yuan, an increase of $16.6 \%$ calculated at comparable prices, and the growth rate declined $0.4 \%$ over January-July, an decline of $0.2 \%$; the total import goods logistics amount was 6 trillion Yuan, an increase of $28 \%$ calculated at comparable prices, and the growth rate declined $0.2 \%$ over January-July, an decline of 2.7 \% (Fig .1). 


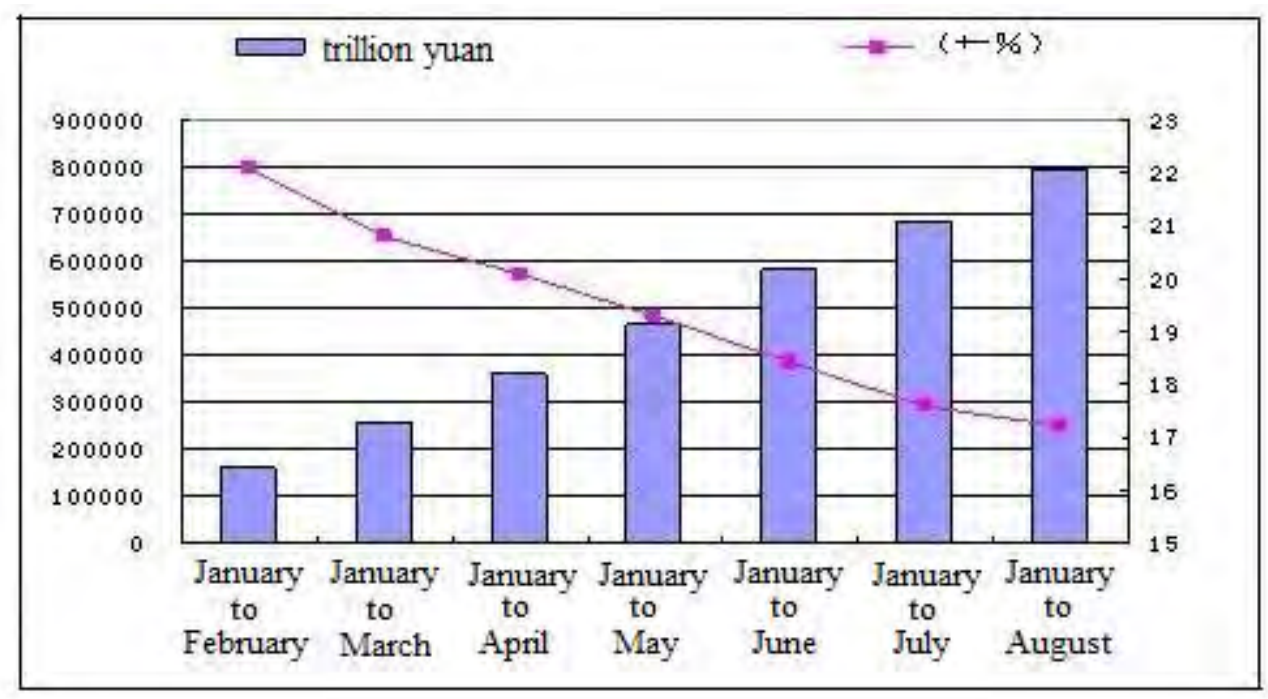

Figure 1. Total development amount of China's logistics

As can be seen, the growth momentum of China's total social logistics amount slowed down, but we can conclude from the traditional development of the logistics industry. On the one hand, since the reform and opening-up, the investment main body of emerging third-party logistics providers in China shows the trend of diversification, the operating mechanisms and market concepts are becoming increasingly market-oriented, but this is just simple exploration and advancement. On the other hand, the logistics enterprises are not familiar with the production operation or have limited capacity, some companies have the phenomena of "logistics site without network and poor network operation" with low utilization rate and low innovation coefficient, the repeated operation makes it is difficult for enterprises to innovate and become inefficient.

\section{B. Foreign capital seizes the Chinese logistics industry}

In recent years, with the deepening of China's reform and opening up, foreign-funded enterprises have gained rapid development in China. Especially being affected by China's WTO accession, the foreign logistics companies supporting the production and circulation enter China, and have produced strong shock wave for China's quiet logistics industry. The most representative are: Mitsubishi established Linghua Warehousing Services Company in Shanghai, China; Raisen Company established a joint venture Baosen with Baosteel.

\section{Restriction factors of China's logistics industry development}

From the asymmetric development of China's logistics industry, various problems emerge during the continuous development: the system adapting to the development of logistics industry has not been established, the logistics service system lags, post logistics have a low social service level and time disorders, and so on. China's logistics industrial development disharmonizes with other industries, and is lack of unified planning of logistics system development. The logistics development policy from the national macro perspective is unclear, lacking guidance for the formation and development of the logistics industry; China's existing logistics infrastructure technology falls behind, the organization and management technology lags, and the construction of logistics network system falls behind; the inherent quality and operational efficiency of logistics need to be improved, the overall logistics potential quality is yet to be vigorously tapped; in the transportation of goods, China's current transportation management system also restricts the efficient convergence between different transport modes, which also slows the logistics speed to a certain extent. Since this year, the overall logistics market price shocks down at low levels. Among them, the composite price index of road freight market was 71.1 in September, a decline of $2.8 \%$, and this issue must be solved promptly.

\section{LOGISTICS TECHNOLOGY}

\section{A. Logistics Technological Innovation and Logistics Information System Collaborative Linkage System Macroscopic Innovation based on RFID}

In modern society, information technology is becoming the core of logistics technology. Therefore, the Collaborative Linkage System of Logistics Technological Innovation and Logistics Information System Macroscopic Innovation based on RFID is mainly reflected in the following two points:

RFID radio frequency identification technology is the basic information gathering means with the modern logistics information management as the guiding principle, which combines with the computer information processing technology, combines with the logical analysis of modern logistics core business, and builds the collaborative linkage system framework of logistics information system.

Through in-depth analysis of the information flow, capital flow, management flow, data flow in the modern logistics information system from all aspects, takes the information processing as the core, study the operation 
logic of RFID in modern logistics information system, and propose the new universal business logic framework of modern logistics information system based on the technology.

\section{B. Prominent features of Logistics Information System collaborative linkage system}

People put more emphasis on information, requiring the realization of logistics and information flow as well as the high online and offline integration, so that the information technology gradually becomes the core of logistics technology. With the development of information technology, network technology and e-commerce technology, modern logistics information technology is an inevitable trend. Information is the foundation of logistics system, information technology and computer technology will fundamentally change the global logistics. Information is reflected as follows: Logistics Information _ commercialization; logistics information collection _ database technology and coding; logistics information processing electronization and computerization; logistics information transfer — networking, standardization and real-time; logistics information storage digitization.

The modern logistics information in logistics activities plays an role similar to the nervous system, which is mainly realized through its several basic functions, including:

1) arket trading activity function. Trading activities primarily record the goods acceptance content, storage arrangement tasks, operating procedures selection, prices setting and related personnel inquiries. The transaction role of logistics information is to record the basic elements of logistics activities. The main features are: procedure, standardization, interactive, emphasizing the efficiency and integration of the entire information system.

2)Service control function. The level and quality of logistics services as well as the management of the existing management individuals and resources shall have the information system for related control, establish the improved evaluation index system to evaluate and identify the operation planning and performance, and emphasize the role of information system as controlling the works and strengthening the control efforts.

3) ordination function. In the logistics operation, strengthen integration and flow of information, which facilitate the work timeliness, improve the work quality and efficiency, reduce the labor intensity factor. The logistics information system can play an extremely important role in the work coordination.

4) support decision-making and strategic functions. Logistics information management coordinates with the staff and management level for activity assessment and cost - benefit analysis, in order to make better decisions. Besides, it highlights the roles of logistics information management system support decision-making and strategic positioning.

Fig. 2 hows the modern logistics activities and decision making on various levels of message function. It is precisely because of the logistics information's important role, the logistics information is managed. In Europe and other developed countries, the logistics output has accounted for a large part of GDP. The contribution of logistics information systems cannot be ignored. Therefore, to become a logistics center in East Asia and Central Asia-Pacific region, China should also put top priority of a modern logistics industrial information technological innovation and logistics information system collaborative linkage system.

\section{JOINT CONSTRUCTION OF LOGISTICS}

TECHNOLOGICAL INNOVATION AND LOGISTICS INFORMATION SYSTEM COLLABORATIVE LINKAGE SYSTEM BASED ON RFID

\section{A. Logistics Technological innovation based on RFID}

The logistics information has experienced the verbal information, text-document information and diverse goods information technology. Materials and goods constantly changing forms in the production and circulation processes, continue to add value, and constantly produce new information. The tracking, identification, authentication, control and feedback of the entire logistics process can gear to e-commerce, improve the marketing skills, and promote the scientific logistics, material requirements and supply. From the technical means, develop from the barcode to two-dimensional code, IC card, RFID, wireless signs, digital encryption, digital watermarking and other technologies; for the management of high-grade goods and upper management, introduce the fingerprint, voice print, retina and other recognition technologies.

RFID (Radio Frequency Identification System, referred to as RFID) is a non-contact automatic identification technology by using the smart electronic tags to identify various items. It has broad application prospects in the manufacturing, retail, logistics, transportation and other industries, which are an indispensable technique and tool for enterprises to reduce costs, improve logistics and supply chain management, and participate in the international economic cycle.

In recent years, with the development of large scale integrated circuits, network communications and information security, RFID technology enters the commercial application stage. Owing to fast-moving object recognition, multiple-target recognition and non-contact recognition features, RFID technology shows great potentials for development and application, being deemed as one of the most promising technologies in the 21 st century. RFID technology has overcome these deficiencies of bar codes, which makes the process automation, and provides real-time data to the supply chain. According to the survey, retail analysts of Forrester Research believe that if using the RFID, Wal-Mart could save 8.35 dollars billion per year, most of which is the human costs of scanning bar codes. In addition, RFID can solve the looses brought by the retail items' out of stock, theft and disturbed supply chain, while Wal-Mart loses 2 billion dollars annually due to theft. Besides, there are also the defects of logistics information asymmetry and untimely 
information access in the logistics process, it is thus difficult to achieve timely regulation and collaboration.

As a result, with the advance of global economic integration, the resources in the links of scheduling, management and supply chain balance (cross regions and cross countries) have become increasingly urgent. From the perspective of the global supply chain formation, as a big manufacturing country, China is the world's manufacturing center as well as an important part of global trade, so it must be geared to the international standards, which is the driving force to form RFID applications. At present, the industrial development has a rapid momentum in China, and
China gets more and more involved in the international bulk trade. Therefore, many domestic enterprises are confronted with a very serious problem, that is, when shortening the gap between the product technology and the world advanced countries, how to integrate our own products into the global supply chain. A realistic fact is that more and more traditional barcode technologies in the international trade are replaced by the RFID technology. If China's relevant industries hope to involve faster and more efficient, it is evitable for them to update the relevant technologies, and the vastest momentum is undoubtedly the RFID technology.

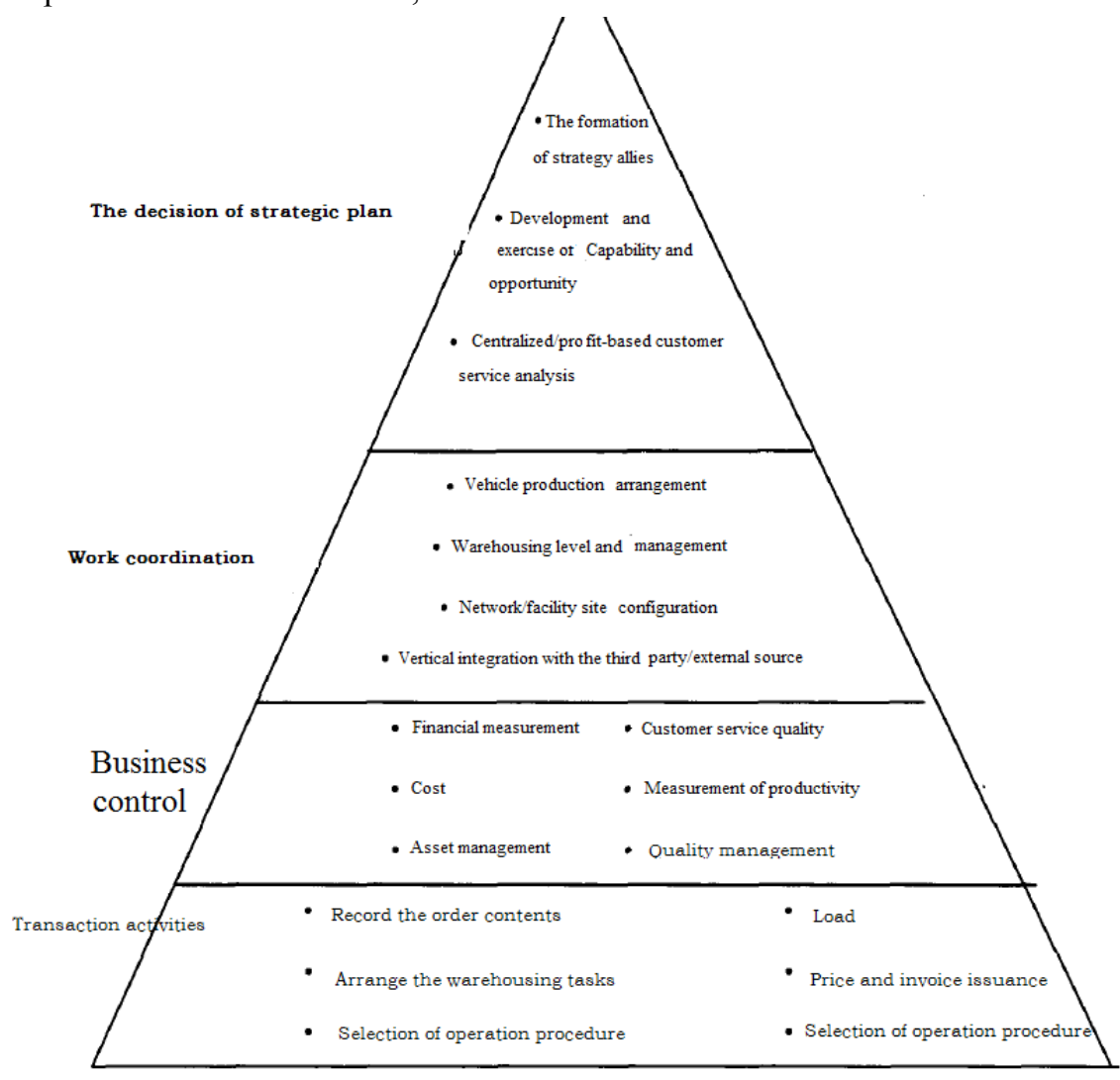

Figure 2. Functional performance of logistics information system collaborative linkage system

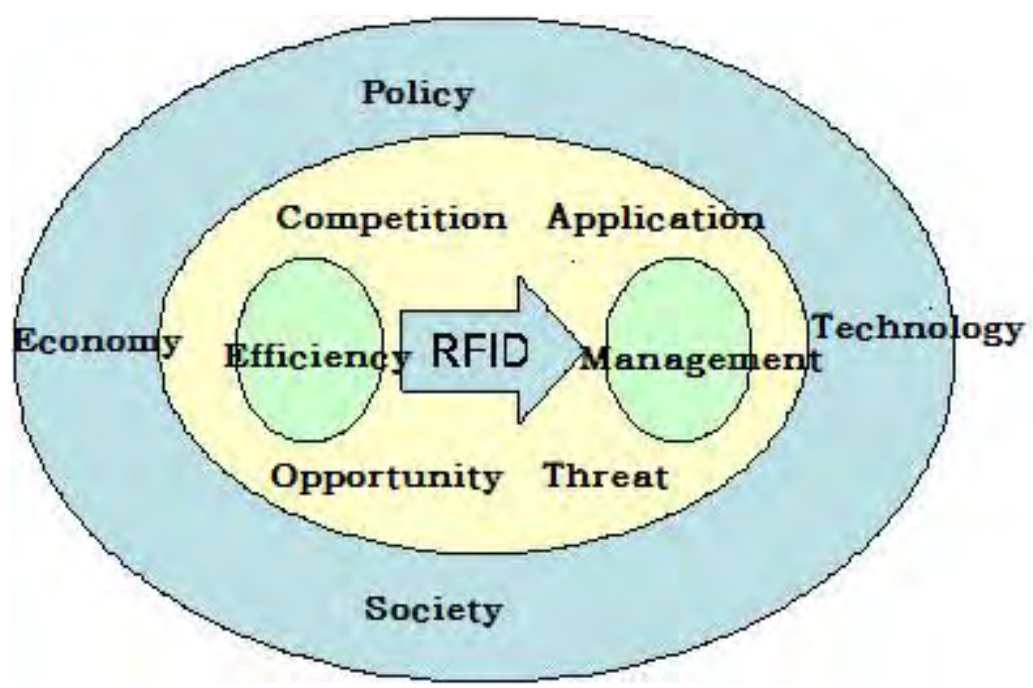

Figure 3. Innovations of RFID technology from multiple aspects 


\section{B. Objectives of logistics innovation technology realization based on RFID}

As can be said, the logistics management information system is the central nervous system of modern logistics, which aims to real-time grasp the news of logistics supply chain, and makes the logistics process as transparent as possible from the online orders to shipping orders, a series of coordination controlled by modern logistics companies and to goods delivery. Therefore, to highlight the crucial role of RFID technology, the following objectives should be realized when building Logistics Technological Innovation and Logistics Information System Collaborative Linkage System based on RFID.

\section{Monitoring of the whole process of logistics}

Take the RFID technology as an information carrier, in order to achieve facilitate the information network to track the product circulation and other links for modern logistics, quickly inquiry and know about the real time information through the Internet, and identify the further production plans, marketing plans and marketing strategies.

\section{Reduce inventory, and improve the business efficiency}

Combine with RFID data collection and information processing technology's efficiency and objectivity, and develop the modern logistics, which is undoubtedly an important way to promote the business logistics activities. The modern logistics providers rely on the carefully planned logistics and timely delivery means to minimize the inventory, improve the cash flow, and achieve the cost advantages. In such a way, the accuracy and rapidity of operations are enhanced, service quality is improved, the costs are reduced, and the labor and inventory space are saved ( $8 \%$ to $35 \%$ ). Besides, the losses incurred from misplacement of goods, wrong delivery, theft, damage and inventory and shipping errors are also reduced.

\section{E. Logistics as the system management}

Traditionally, the logistics is only a general business activity, and the logistics information is often scattered in different departments. Today logistics has been regarded as the third profit source of enterprises, while the enterprises pursue the integrated management from procurement, production and sales. Under the environment of supply chain integration management, management and coordination of logistics and information flow enable information to freely and accurately flow, which becomes more important.

\section{F. Effectively support efficient logistics services}

With the support of RFID technology, regardless of the transport modes, transit links, whether to assemble, to ensure the correct identification of the same consignment, guarantee the coordination of transportation, warehousing and other links, accurately and timely complete the logistics commands in all aspects.

\section{G. Effectively support the distribution, packaging, processing and other value-added logistics services}

The logistics service providers can design various value-added business models according to customer needs, and combine new management concepts and advanced management technology with the information system.

\section{H. Structural design of Logistics collaborative linkage system based on RFID}

The core supporting point of introducing RFID technology in the modern logistics industry lies in the reliable, massive, fast, secure information processing of RFID tags. Based on the massive data throughput requirements of modern logistics, it is necessary to introduce the effective data transfer, storage and collection techniques. Logistics Information Management is a process of logistics information collection, collation, storage, dissemination and utilization, that is, the process of scattered logistics information to centralized, from disorder to order, from generation, dissemination to utilization. Besides, realize the reasonable allocation of the various elements related to the logistics information activities, including personnel, technology and tools. Effective management of information is to emphasize the accuracy, validity, timeliness, integration and sharing of information. Therefore, in the process of information collection and collation, avoid the information defects, distortion and failure, strengthen the organization and control of the logistics information process activities, and establish effective management mechanism. In addition, strengthen the exchange. Only by transmission can information generate values, so there must be an information exchange and sharing mechanism to facilitate the formation of information accumulation and advantage conversion.

The logistics technology means the modernization of logistics means. Therefore, apply the RFID information logistics collaborative linkage system to the actual logistics information management, give full play to the role of collaborative systems based on RFID technology, realize the modern logistics objectives by using the advanced technology, equipment and management, and enable the logistics process to be more transparent and accurate through the wide application of computer information technology.

Information is the soul of modern logistics. Collaborative logistics information system enables the information scattered in different economic sectors and different companies to realize the exchange and sharing of information, so as to effectively coordinate, manage and integrative operation of various logistics elements and functions. While giving the RFID technology into full play, concern about the development of derivative technologies to promote the application of modern information management technologies in logistics companies and businesses logistics management, such as ERP, MRP, and vigorously promote the construction of public information platform, build a sound 
e-commerce certification system, online payment system and logistics management system, and create conditions for the smooth and efficient exchange of logistics information. Therefore, the integration of information logistics collaborative linkage system can be truly achieved.

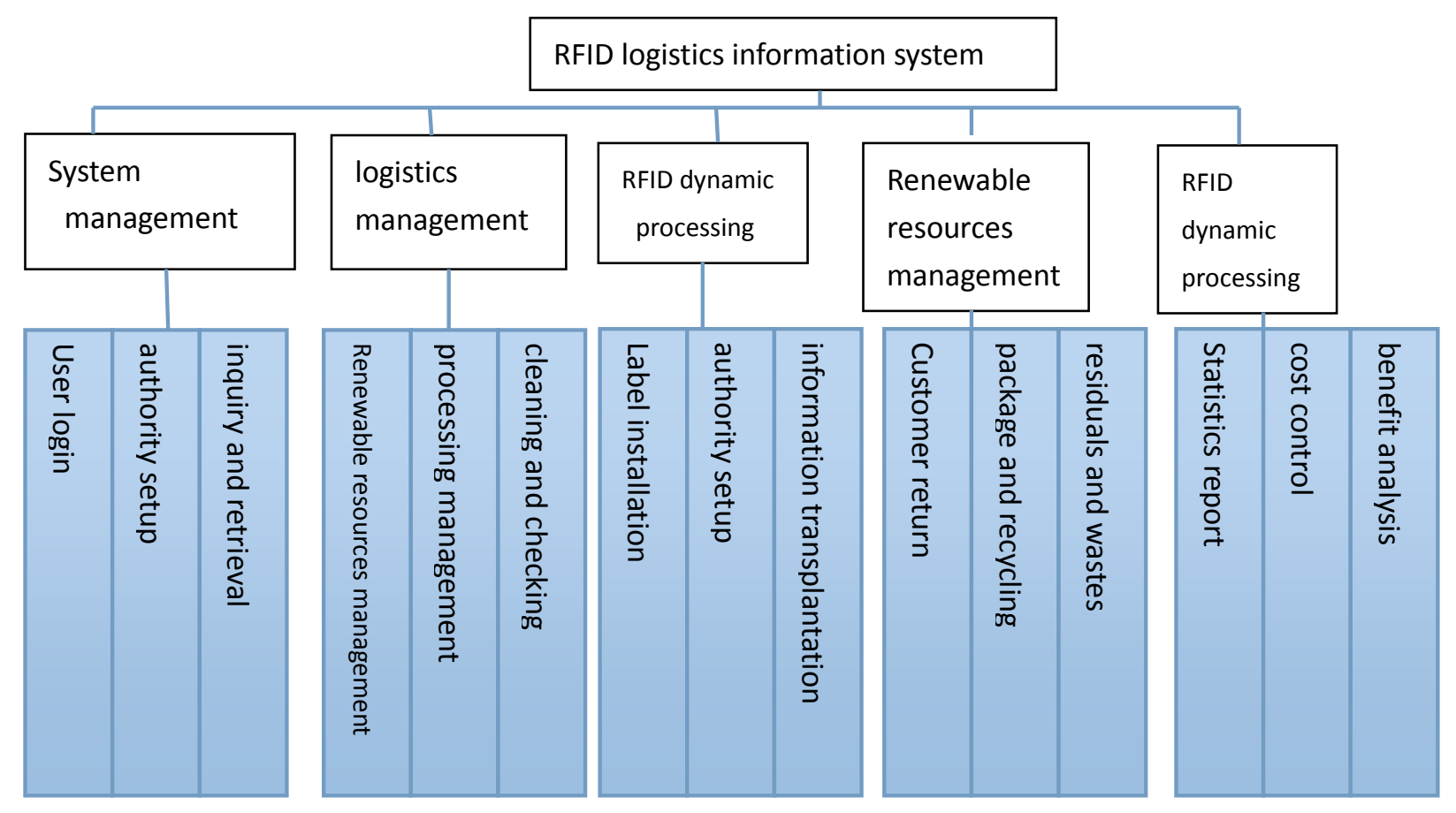

Figure 4. tructural design of Information logistics collaborative linkage system based on RFID

\section{CONCLUSION}

At present, the modern logistics industry is facing a brand new development environment, showing some prominent trends: the rapid development of logistics technology, continuous improvement of logistics management, which has formed the modern logistics technological pattern with the information technology as the core, transportation technology, distribution technology, handling technology, automation warehousing technology, inventory control technology and the professional technology of packaging technology, and the construction of logistics information technological innovation and logistics information system innovation collaborative linkage system based on RFID also comply with the pace of social advance.

The intelligent integration of logistics information technological innovation and logistics information system innovation collaborative linkage system based on RFID fully depends on modern logistics enterprises to be intensive, collaborative, globalized pace. With the rapid development of e-commerce, Internet Online logistics will gradually become a revolutionary element due to its rapid, timely, diversification and low-cost high-yield advantages in the modern logistics development under the logistics information coordination system.

\section{REFERENCES}

[1] Shi Jianzhong. The government should lead the RFID application for the underpowered enterprises [J]. Information Systems Engineering . 2013 (05)

[2] Yun Xiaobei. Frequency identification, tag the world [J]. Chinese investment. 2012(05)

[3] Shi Jianzhong. Who cross the barriers of RFID [J]. Information Systems Engineering. 2011(01)

[4] Lv Yong, Li Yuanhong. Standardization promotes the RFID industrial development [J]. World Standardization \& Quality Management. 2013 (11)

[5] Wang Wei. Countermeasures for China's logistics industry to adapt to the development of modern information technology [J] Financial and Economics. 2013 ( 01 )

[6] Shi Xianliang, Zhou Jianqin, Lin Zikui. Construction of logistics information platform to promote the development of modern logistics [J]. China Logistics and Purchasing. 2013(01)

[7] Mou Weizhong. Exploration on modern logistics [J]. Logistics Technology. $2000(01)$

[8] He Jingshi, Yan Hanjun, Zhang Zhiyong. Transformation and upgrading of logistics industrial growth pattern based on the technological integration [J]. Ecological Economy. 2013(06)

[9] Shen Xiangyang. Research on necessity of logistics enterprise technological innovation at current stage [J]. Logistics Technology. 2012 (11)

[10] Zhang Qihui. Research on enterprise logistics innovation based on complex adaptive system (Manufacturing) [D]. Huazhong University of Science and Technology. 2013

[11] Li Yibo, Zhang Zhiyong. Design of visible logistics management information system based on GPS and GIS [J]. Metallurgical Industry Automation. 2013 (05)

[12] Zhang Hongyan. logistics distribution Information system based on network [J]. Journal of Changchun Institute of Technology (Natural Science). 2012 (04) 